\title{
Xeroderma Pigmentosum, Complementation Group E
}

National Cancer Institute

\section{Source}

National Cancer Institute. Xeroderma Pigmentosum, Complementation Group E. NCI

Thesaurus. Code C114771.

An autosomal recessive genetic disorder caused by mutations in the DDB2 gene. This disease exhibits the mildest degree of sun sensitivity of all xeroderma pigmentosum complementation groups, although individuals are at high risk for skin cancer. 